\title{
"Um sentido muito próximo ao que propõe a educação permanente em saúde"! O devir da educação e a escuta pedagógica da saúde
}

Ricardo Burg Ceccim ${ }^{1}$

Um texto: "O trabalhador moral na saúde: reflexões sobre um conceito"; um autor: Luiz Carlos de Oliveira Cecílio; um veículo de divulgação científica: Interface - Comunicação, Saúde, Educação; uma sessão: debate. Pois bem, busco algumas palavras-chave que me sejam "muito próximas" e encontro: saúde, trabalho em saúde, trabalhadores de saúde, educação na saúde, educação permanente em saúde, interface, comunicaçãosaúde-educação... Tenho escrito e pensado sobre essa correlação: trabalho-saúdeeducação.

Cecílio nos deixa ver que em noções como a de recursos humanos da saúde, algo mais transborda que não devém da teoria administrativa, desde que se detectou o fator humano nas organizações. Comenta que com "atores em ação", tratar-se-ia, então, de criar e operar novas categorias e conceitos que fizessem sentido para suas práticas, a partir de suas práticas, "num sentido muito próximo ao que propõe a educação permanente em saúde", lembrando de teóricos desse referencial conceitual e de um texto meu na Interface (Ceccim, 2005). O que é interessante é que Cecílio puxa como fios de análise uma teoria do trabalho, particularmente relativa ao processo de condução do trabalho. Traz, então, a noção de uma teoria da ação e põe em cheque o projeto fayolista (Henri Fayol) de comando organizacional. Se Frederick Taylor apresentou os princípios da administração científica, Henri Fayol somou-Ihe a racionalidade gerencial hegemônica. Nas teorias relativas ao fator humano nas organizações (os recursos humanos na teoria da administração) vemos correr as formulações de um homo economicus, um homo socialis, um homem administrativo, um homem funcional e, finalmente, um homem complexo (a revisão é de Rosa, 2003), mas Cecílio vem interrogar-nos sobre a possibilidade, em particular, de um anti-Fayol na condução do trabalho em saúde.

Isso ocorre porque é de Fayol a obsessão pelo comando e heterodeterminação dos trabalhadores, podendo-se supor uma regência fayolista nos modos de ser profissional onde a autonomia como autocriação/autopoiese, liberdade de engendrar-se ou capacidade de interagir consigo mesmo está desqualificada sob a imagem de uma autonomia regulada desde fora, desde os imaginários profissionais, desde as representações de poder e desde as hierarquias ou burocracias. Essa imagem de autonomia, não a autonomia, constitui mecanismo de captura, uniformização e padronização. Não a abertura aos modos de ser, estar, sentir ou conhecer, mas a subordinação aos modos dados e ao controle da realidade pelas racionalidades hegemônicas. O poder de legitimidade nas relações e nos processos de trabalho, o submeter-se às regulamentações legais e às regulações normativas dadas desde fora (desde antes, desde sempre e para sempre) aparecem como autonomia em organizações comandadas e não a abertura ao demandado aqui-e-agora nas ações atuais do trabalho (atual com o sentido foucaultiano de perfusão do real - o vigente - pela potência de novas realidades - o virtual).

\footnotetext{
${ }^{1}$ Enfermeiro sanitarista; doutor em Psicologia Clínica; professor, Programa de Pós-Graduação em Educação, Universidade Federal do Rio Grande do Sul (Ufrgs). Porto Alegre, RS. <burg.ceccim@ufrgs.br>
} 
Gastão Campos já nos havia proposto o anti-Taylor, em 1998, nos Cadernos de Saúde Pública, sugerindo a invenção do método de gestão colegiada centrada em equipes de saúde. O autor citava produção de Cecílio de 1994, que já estudava os processos de condução do trabalho em saúde (Cecílio, 2006) e o desafio era o de uma gestão que produzisse liberdade e compromisso (Campos, 1998).

Na teoria da Administração Científica, Taylor e Fayol representam o pensamento inaugural, mas podemos acrescentar Mayo e Weber na tradição da teoria administrativa. Com Elton Mayo surge a teoria das relações humanas (surgem as "pessoas", uma compreensão de que os trabalhadores constroem relações e estas superam a simples distribuição de funções na produção do trabalho). Max Weber estruturou a organização como um modelo (burocrático) e, assim, instituiu uma noção de atividades-meio e atividades-fim, o que colocava o homem (recursos humanos ou pessoas) como adequação aos fins (objetivos) do empreendimento sob o trabalho. Os recursos humanos ou as pessoas seriam, então, recursos ou insumos que se prestariam a dar condições para que os objetivos finalísticos de uma organização fossem alcançados.

Cecílio lembra-nos que a expressão gestão de pessoas está imbuída da concepção gerencialista hegemônica, fala-se de gestão de pessoas do mesmo modo que de gestão de insumos, gestão de estratégias etc. A terminologia inicial, a dos recursos humanos, colocava os humanos entre os recursos administrativos, como os recursos materiais e os recursos financeiros. Taylor pensava o trabalho como uma engenharia da produção, Fayol o propõe como um processo organizacional. Para o primeiro, o homem é fator de produção e para o segundo o componente social nas organizações. Com Mayo esse componente ganha o estatuto psicológico e surgem as pessoas, cujo processo de gestão pode potencializar a produção e a adesão ao trabalho comandado na organização. Com Weber essa gestão está entendida e localizada no segmento meio para atingir os fins.

Quando Cecílio diz, entretanto, que nas relações de cuidado à saúde algo transborda, afirma que não é possível a subordinação das pessoas pelo processo de trabalho, mesmo que constrangidas ou sob a disputa de captura da sua subjetivação, mas mais do que isso diz que não será possível incentivar a autonomia aquele que nela ou por ela não se produz e aos seus entornos. Surge, então, um outro parceiro de pensamento, Emerson Merhy, que em 1997 propôs o conceito de micropolítica do trabalho vivo em saúde, em Agir em saúde: um desafio para o público, sugerindo a existência de uma questão institucional e do território das tecnologias leves (Merhy, 2007). O autor também referia Cecílio na construção de suas reflexões.

O transbordamento está na emergência de um espaço de acoplamento profissionalusuário, resultado do encontro em que ocorrem a escuta de sintomas, o perscrutar possibilidades diagnósticas e terapêuticas, o conectar-se ao outro para detectar seus sentidos e oferecer guarida, tratamento e orientações que toquem o próprio viver. Eu mesmo, também em 1997, em Exclusão da alteridade: de uma nota de imprensa a uma nota sobre a deficiência mental, tomava o tema do outro, denunciando a exclusão da alteridade nas relações de cuidado (Ceccim, 2006). É que sem as conexões de alteridade a autonomia está estasiada (plegia da autonomia). O que Cecílio vai "pinçar" por sua vez, é que o trabalhador que se exclui do que agora vou chamar acoplamento de alteridade não contribui "para o fortalecimento da autonomia daquele de quem cuida", o que equivaleria dizer não exerce efetivo cuidado, uma vez que este infundiria autocriação, capacidade de interagir consigo mesmo, conhecer-se mais e pôr-se em produção de si. Por outro lado, uma construção do si mesmo profissional, "cultivada e amadurecida", como fala Cecílio, também está na ordem do encontro estabelecido com seus usuários. Ana Pitta, já em 1990, lembrava que a maior proteção psíquica dos trabalhadores em hospital (convivendo com a dor e a morte como ofício) estava na maior conexão afetiva com os usuários e não no distanciamento técnico. É que a autonomia somente se engendra e se exerce no acoplamento à autonomia do outro: encontro de autonomias, o que é da especificidade do trabalho em saúde e somente comparável ao trabalho em educação, particularmente o do ensino fundamental (Pitta, 2003).

Cecílio conduz-nos, então, às formulações "atores em ação de trabalho" e "prática gerencial libertária e inovadora", atores em ação de trabalho numa prática gerencial libertária e inovadora, não mais a gestão de recursos humanos ou a gestão de pessoas quando e se estivermos engajados no processo de construção do Sistema Único de 
Saúde. "O anti-Fayol é possível?" - pergunta-nos. "Haveria uma sétima função gerencial a ser inventada?" - é a provocação do autor, mas ele também entabula: "Como enunciar esta nova função administrativa?"

Pois bem, eu responderia, primeiro com o seu próprio texto e, a seguir, com minhas últimas formulações, as quais devêm de um leitor amante do que escreveram Cecílio, Merhy e Campos nos termos em que Cecílio pontuou no seu texto ("meu texto só existe pelo meu convívio, íntimo e prolongado, com Gastão Campos e Emerson Merhy"). No meu caso, reformularia para: meu texto existe pela leitura apaixonada da escrita em convívio de Gastão Campos, Emerson Merhy e Luiz Cecílio (Planejamento sem Normas, Inventando a Mudança na Saúde, Agir em Saúde). A primeira resposta projetada é: segundo Cecílio (2007), deveria ser formulada uma sétima função gerencial, esquecida por Fayol e que converte a gestão organizacional em projeto anti-Fayol. Esta sétima função é o "interrogar" 2. Para o autor, o ato de interrogar é a possibilidade de curso a qualquer projeto/processo de gestão. "Toda a pretensão de se conduzir mudanças verdadeiras na forma de fazer a gestão e de se organizar o cuidado em saúde" inicia pela "capacidade de aprender a interrogar o mundo do trabalho, antes de propor, aprioristicamente, conceitos e/ou modos muito prescritivos de se fazer a gestão". A segunda resposta é: eu penso que a sétima função é a educação permanente em saúde (resposta validada pelo próprio autor, como retomei no título deste debate), mas para aí trago o devir da educação (conduzir às aprendizagens, construir o conhecimento, compartilhar experiências de problematização, organizar práticas educativas, compor coletivos de aprendizagem/círculos de cultura, produzir o desenvolvimento por desafios sócio-interacionistas, fazer emergir novos saberes e fazeres pela exploração problematizadora dos saberes e fazeres vigentes, entre outros processos próprios das relações de ensino-aprendizagem) e a escuta pedagógica da saúde (interrogar o processo de trabalho em saúde pelas questões educativas: ocorre o compartilhamento de problematizações? Como ocorre a composição de coletivos de aprendizagem? Como ocorrem o desenvolvimento e a aprendizagem?). O devir da educação está vivo na noção de educação permanente em saúde (Ceccim, 2005); a escuta pedagógica em saúde (Ceccim, 2007; Ceccim et al., 2007) estabelece uma atenção à organização de saúde (processos, serviços, sistemas), não para tomá-la em seu "o que é/como está" ou "o que deve/como deve" ser/estar, mas ao que pede atualização, processo de mudança, emergência de saberes e fazeres novos, construção pedagógica.

Cecílio intensifica nossa reflexão pela provocação "trabalhador moral", alertando para uma compreensão não idealizada da micropolítica e de que não se pode não desejar a autonomia, porque assim não haveria o cuidado que quer a autonomia do outro na singularização de sua saúde (o seu andar a vida). A idealização da micropolítica é já a sua conversão em dever moral, anulando sua condição de indicar o componente desejante/pulsátil (vibração do criar/inventar) nas instituições e a simples adesão aos projetos no governo ("por mais justos e puros que sejam", como ele ressalva) não diferem da visão administrativa do homo socialis, manejado como homem funcional, visão gerencialista que subestima e rejeita o protagonismo e a força instituinte (vibrátil). Um gestor somente pode ser disparador, disruptor, agenciador, para isso usufrui do poder de introdução de dispositivos gerenciais (a macropolítica representada pelo projeto de governo, projeto de gestão). Sabemos que muito mais que acolher projetos de governo e projetos de gestão, os trabalhadores trazem para o trabalho outros antecedentes (deveres morais), principalmente as designações de suas corporações profissionais (não por acaso as mesmas investem tanto em tecnologias do imaginário), posicionando-se como homens da moral, não como homens da ética. Cecílio foi claro e, servindo-se de Nietzsche, apresenta o trabalhador moral como um homem do dever, envolto numa malha de deveres. Este é o trabalhador moral, refém dos valores, adesista aos governos, ventríloco dos teóricos e das nomeações da teoria. Estes não são os bons cuidadores de vidas que pedem atualidade, singularidade, novidade.

O que Cecílio talvez não intensifique em seu texto tanto quanto ativa como desafio no campo é o pensamento sobre o papel da intervenção organizacional em situação de governo (em lugar de uma luta permanente contra o Fayol que insiste em se instalar nos gestores, não tolerando autogoverno/autogestão), o assumir a micropolítica por toda parte (aceitar que nada está garantido, nada é desde sempre, nem para sempre,
${ }^{2}$ As seis funções administrativas de Fayol citadas por Cecílio, são: administrar, prever, organizar, comandar, coordenar e controlar. 
ativando-se a auto-análise e a autogestão - numa perspectiva libertária e inovadora) e as tecnologias de captura da produção de sentidos (anulação da autonomia por sua tradução na subordinação aos instituídos como imagem de poder e sucesso, anulação da força instituinte dos processos libertários e inovadores). Cecílio nos põe mais provocações no campo, o que é absolutamente desejável.

\section{Referências}

CAMPOS, G.W.S. O anti-Taylor: sobre a invenção de um método para co-governar instituições de saúde produzindo liberdade e compromisso. Cad. Saúde Pública, v.14, n.4, p.863-70, 1998.

CECCIM, R.B. Invenção da saúde coletiva e do controle social em saúde no Brasil: nova educação na saúde e novos contornos e potencialidades à cidadania. Estud. Univ., v.33, n.1, 2007. (no prelo)

Exclusão da alteridade: de uma nota de imprensa a uma nota sobre a deficiência mental. In:

SKLIAR, C. (Org.). Educação e exclusão: abordagens sócio-antropológicas em educação especial. 5.ed. Porto Alegre: Mediação, 2006. p.15-36.

Educação permanente em saúde: desafio ambicioso e necessário. Interface - Comunic., Saúde, Educ., v.9, n.16, p.161-8, 2005.

CECCIM, R.B.; GUIMARÃES, A.R.; KLAFKE, T.E.; LENZ, F.L. Autogestão no trabalho com/em equipes de saúde: estudantes agindo o Sistema Único de Saúde. In: PINHEIRO, R.; BARROS, M.E.B.; MATTOS, R.A. (Orgs.). Trabalho em equipe sob o eixo da integralidade: valores, sabres e práticas em debate. Rio de Janeiro: Cepesc, 2007. (no prelo)

CECÍLIO, L.C.O. O "trabalhador moral" na saúde: reflexões sobre um conceito. Interface - Comunic., Saúde, Educ., v.11, n.22, 2007.

Inventando a mudança na saúde. 3.ed. São Paulo: Hucitec, 2006.

MERHY, E.E. Em busca do tempo perdido: a micropolítica do trabalho vivo em saúde. In: MERHY, E.E.;

ONOCKO, R. (Orgs.). Agir em saúde: um desafio para o público. 3.ed. São Paulo: Hucitec, 2007. p.71-111.

PITTA, A. Hospital: dor e morte como ofício. 5.ed. São Paulo: Hucitec, 2003.

ROSA, I.L.I. O homem e o trabalho administrativo. Cad. Pesqui. Admin., v.10, n.4, p.1-7, 2003. 